\title{
ABUNDÂNCIA DE MACROCRUSTÁCEOS DECÁPODAS NAS ÁREAS RASAS DO COMPLEXO LAGUNAR MUNDAÚ/MANGUABA, AL
}

\author{
ROGÉRIO L. TEIXEIRA ${ }^{1}$ e HÉLIO S. SÁ ${ }^{2}$ \\ ${ }^{1}$ Museu de Biologia Mello-Leitão, Av. José Ruschi, 4, CEP 29650-000, Santa Teresa, ES \\ ${ }^{2}$ Departamento de Biologia, Universidade Federal do Espírito Santo, \\ Av. Marechal Campos, 1468, CEP 29040-090, Vitória, ES \\ Correspondência para: Rogério L. Teixeira, Rua Bernardino Monteiro, 75, Centro, CEP 29650-000, Santa Tereza, ES \\ Recebido em 27/02/97 - Aceito em 29/05/98 - Distribuído em 28/08/98
}

(Com 7 figuras)

\begin{abstract}
Abundance of decapod macrocrustaceans occupying the shallow waters of a tropical estuary

The macrocrustaceans occupy the shallow waters of Mundaú/Manguaba lagoonal system, located in Maceió, AL, northeastern Brazil, were studied from May 1988 to April 1989. Samples were taken with a beach seine. It was collected 15 species belonging to 6 genera and 3 families. Dominant species in number were: Palaemon pandaliformis, followed by Macrobrachium acanthurus and Callinectes danae. Dominant species in biomass were: $C$. danae, followed by C. bocourti, P. pandaliformis, $M$. acanthurus and $C$. ornatus. Dominant species occurred throughout the year and in most stations. Cluster analysis based on the abundance by month and stations showed the presence of two main group of species: Group I dominated by portunids, and group II dominated mainly by palaemonids. As macrocrustaceans are important fishery resources inside the estuarine area, its necessary the development of a better management plan for local authorities in order to guarantee the renewal of stocks.
\end{abstract}

Key words: Callinectes, Macrobrachium, Palaemon, estuary, mangrove.

\section{RESUMO}

Os macrocrustáceos que ocorrem nas partes rasas do complexo lagunar Mundaú/Manguaba foram estudados entre maio de 1988 e abril de1989. As amostragens foram realizadas com rede de arrasto de praia. Foi capturado um total de 15 espécies pertencentes a 6 gêneros e 3 famílias. Baseado no CPUE, as espécies que predominaram em número foram: Palaemon pandaliformis, seguido por Macrobrachium acanthurus e Callinectes danae. Com relação à biomassa, as espécies dominantes foram: $C$. danae, seguido por $C$. bocourti, P. pandaliformis, M. acanthurus e C. ornatus. Análises de agrupamento por mês e estação de coleta evidenciaram a associação de dois grupos de espécies: um dominado por portunídeos e outro por palaemonídeos. Como os macrocrustáceos representam importantes recursos pesqueiros, é necessário o desenvolvimento de melhores planos de manejo dentro do estuário para garantir a renovação dos estoques.

Palavras-chave: Callinectes, Macrobrachium, Palaemon, estuário, mangue.

\section{INTRODUÇÃO}

Os macrocrustáceos representam importantes elementos dentro das comunidades dos ecossistemas costeiros, tendo importante papel na pescaria artesanal, comercial e recreacional.
Além de sua importância para o consumo humano, os macrocrustáceos representam importantes presas para a maioria dos organismos carnívoros que ocupam os ecossistemas aquáticos costeiros, seja no estágio larval ou na forma adulta. 
Sistemas lagunares tropicais e rasos localizados entre barreiras de recifes e a parte continental incluem uma diversidade de habitats, como leitos de vegetação aquática submersa e manguezais (Sedberry \& Carter, 1993), as quais criam condições favoráveis para o fornecimento de novos microhabitats para muitos organismos.

Estes ambientes costeiros normalmente se caracterizam por apresentar uma comunidade diversa, cujas estratégias variam desde espécies dependentes do local, espécies visitantes ocasionais e aquelas espécies que ocorrem esporadicamente. A riqueza de habitats atrai muitos organismos, sendo que a presença de uma diversidade de presas potenciais termina por atrair também muitos predadores.

Os macrocrustáceos representam importantes recursos pesqueiros principalmente para as populações de baixa renda que habitam próximas às regiões estuarinas. No nordeste do Brasil, a importância destes organismos tem levado ao desenvolvimento de várias pesquisas, as quais têm se dedicado principalmente à sistemática, taxonomia e levantamentos de espécies (por exemplo, Coelho \& Ramos, 1972; Coelho et al., 1990; Coelho \& Lacerda, 1990; Coelho \& Regis, 1990; Coelho \& Santos, 1990; Ramos \& Coelho, 1990, entre muitos outros).

Em particular para o estado de Alagoas, destacam-se os trabalhos de Pereira-Barros
(1981), que trata da ocorrência das espécies pertencentes ao gênero Callinectes dentro do complexo estuarino Mundaú/Manguaba; Coelho et al. (1990), o qual apresenta uma lista dos crustáceos decápodas para o estado; e Silva (1992), que avalia a distribuição e a abundância da fauna macrobentônica em Mundaú/Manguaba.

Como a maioria dos estudos sobre a carcinofauna do complexo estuarino Mundaú/Manguaba não apresenta uma avaliação estatística relacionada com a distribuição, abundância, sazonalidade e as relações com fatores abióticos, este estudo visa complementar o conhecimento sobre os aspectos ecológicos que envolvem as populações de macrocrustáceos do estuário em questão. Consideramos as espécies que compõem a comunidade de macrocrustáceos do ambiente estuarino, suas abundâncias e relações com os principais fatores abióticos através de análise de componentes principais.

\section{MATERIAL E MÉTODOS}

\section{Área de Estudo}

O complexo lagunar Mundaú/Manguaba, situado em Alagoas, tem uma área aproximada de $55 \mathrm{~km}^{2}$, sendo constituído pelas lagoas de Mundaú e Manguaba. Estas lagoas são interligadas por uma série de canais que convergem para uma única desembocadura (Fig. 1). O Rio Mundaú é o

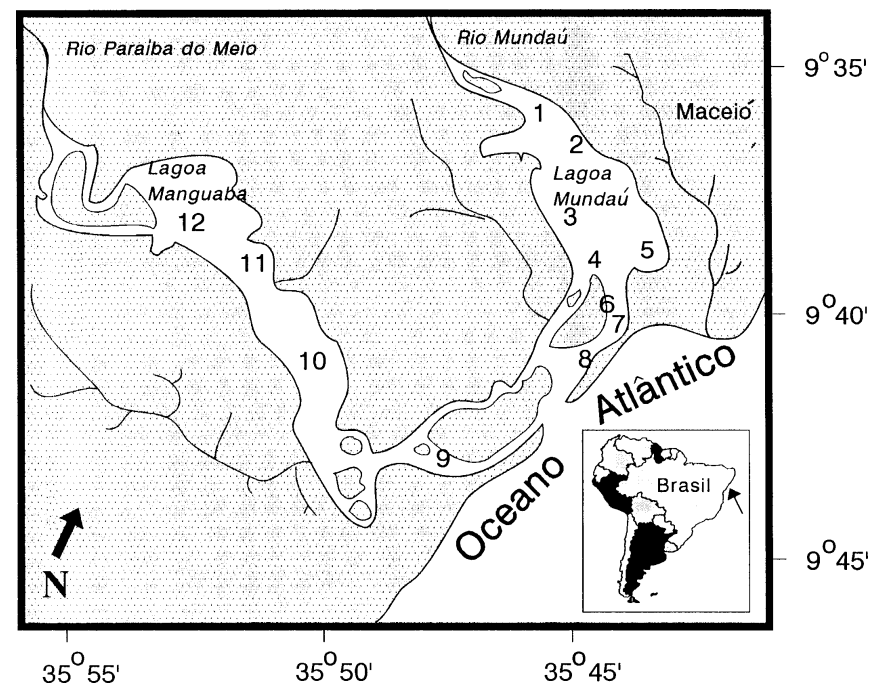

Fig. 1 - Área de estudo evidenciando as 12 estações amostradas nas partes rasas do complexo lagunar Mundaú/Manguaba, Maceió, AL. 
principal fornecedor de água para a Lagoa de Mundaú, enquanto o Rio Paraíba do Meio é o principal fornecedor de água para a Lagoa Manguaba. O complexo estuarino está situado entre as latitudes de $9^{\circ} 36^{\prime} \mathrm{S}$ e $9^{\circ} 45^{\prime} \mathrm{S}$, e entre as longitudes de $35^{\circ} 41^{\prime} \mathrm{W}$ e $35^{\circ} 55^{\prime} \mathrm{W}$. Maiores detalhes sobre a área de estudo encontra-se em Teixeira \& Falcão (1992).

\section{Procedimento Amostral e Análises Estatísticas}

Foram selecionadas 12 estações fixas localizadas nas áreas rasas para representar a carcinofauna do complexo estuarino. Segundo Teixeira (1994), o ambiente foi dividido em quatro subsistemas: 1) Lagoa Mundaú (estações: 1-5); 2) Mangue (estação 6); Canais (estações: 7-9) e; 4) Lagoa Manguaba (estações: 10-12). De maio de 1988 a abril de 1989 , foram realizadas mensalmente amostragens diurnas, com uma rede de arrasto de praia tipo "picaré" (15 m x $2 \mathrm{~m}$; malha: $5 \mathrm{~mm}$ ). Três lances consecutivos e paralelos à margem foram feitos em cada estação. Os organismos foram fixados em álcool a 70\% após cada lance. Em cada estação foram registrados a temperatura $\left({ }^{\circ} \mathrm{C}\right)$, salinidade $(\% o)$, transparência $(\mathrm{m})$, profundidade $(\mathrm{m})$, distância do mar $(\mathrm{km})$ e tipo de substrato (1- argila; 2- lama; 3- areno-lodoso; 4- cascalho; 5- areia). Dados de vazão $\left(\mathrm{m}^{3} / \mathrm{s}\right)$ foram cedidos por Arno Oliveira (com. pes.). No laboratório, os organismos foram identificados, contados e pesados.

A abundância numérica e a biomassa por mês e estação foram avaliadas de acordo com a captura por unidade de esforço (CPUE). As diferenças da abundância numérica por mês e por estação de coleta das 6 espécies mais importantes foram comparadas estatisticamente empregando-se a análise de variância (ANOVA) com um critério. Antes de empregar a ANOVA, usamos o teste de Bartlett para avaliar a homocedasticidade das amostras. Após este procedimento, os dados foram transformados em $\log _{10}(x+1)$, quando necessário, com a finalidade de atingir os pressupostos do teste paramétrico. Foram feitas análises de agrupamentos (UPGMA) baseadas na distância Euclidiana para avaliar as possíveis similaridades nas abundâncias por mês e estação das 10 espécies que ocorreram em mais de $15 \%$ das amostras.

Também examinamos as variações na abundância das 10 espécies mais relevantes com aná- lise dos componentes principais de sete variáveis ambientais baseados em matriz de correlação. As variáveis ambientais foram usadas para calcular o peso de cada fator (variáveis artificiais) a fim de gerar os escores dos componentes principais em cada amostra (Sokal \& Rohlf, 1981). Após este procedimento, as espécies foram plotadas em um gráfico consistindo apenas dos três fatores mais importantes, os quais representam a resposta numérica da população de acordo com as variáveis ambientais. No procedimento, foram considerados apenas os fatores cujo autovalor foi maior do que 1,0 . No procedimento, foi considerada a opção com rotação de variâncias ("varimax rotation”) (Mulaik, 1972).

\section{RESULTADOS}

Dentro dos subsistemas, a temperatura média variou de $26,5^{\circ} \mathrm{C}$ na Lagoa Manguaba (inverno) até $35,7^{\circ} \mathrm{C}$ no mangue (verão) durante maré baixa. A salinidade média variou de $0,6 \%$ na Lagoa Manguaba no inverno (período de chuvas) até $19,7 \%$ o nos canais durante o verão (período de seca). A transparência variou de 0,2 a $1,1 \mathrm{~m}$. Os valores mínimos de transparência, de uma maneira geral, ocorreram durante o período de cheia em todo o sistema, e durante todo o ano nas estações próximas dos rios. $\mathrm{O}$ menor valor médio mensal da vazão foi de $3,3 \mathrm{~m}^{3} / \mathrm{s}$ em fevereiro, e o máximo foi de $105,7 \mathrm{~m}^{3} / \mathrm{s}$ em julho.

Foi capturado um total de 15 espécies pertencentes a 6 gêneros e 3 famílias (Tabela 1). Com base no CPUE, as espécies que predominaram em número foram: Palaemon pandaliformis, seguido por Macrobrachium acanthurus e Callinectes danae. Com relação à biomassa, as espécies dominantes foram: $C$. danae, seguido por $C$. bocourti, P. pandaliformis, M. acanthurus e $C$. ornatus.

A Figura 2 compara as abundâncias, em número e em biomassa, das espécies dominantes de acordo com os subsistemas. Callinectes danae foi mais abundante na Lagoa de Mundaú, $P$. pandaliformis, nos canais de ligação entre as lagoas e no mangue, enquanto $C$. bocourti e $P$. pandaliformis predominaram na Lagoa Manguaba.

Foi feita a análise da variação da abundância numérica, por mês e por estação, das três espécies mais abundantes de Callinectes (Fig. 3). Callinectes danae ocorreu em todos os meses 
amostrados e em quase todas as estações. Esta espécie foi mais abundante numericamente em maio e junho, especialmente nas estações mais relacionadas com os canais de ligação entre as lagoas. Entretanto, não houve diferenças significativas nas capturas por mês (ANOVA: $\mathrm{F}_{11,127}=1,75 ; \mathrm{P}>$ $0,0703)$, mas as capturas foram significativamente diferentes por estação (ANOVA: $\mathrm{F}_{11,127}=8,81 ; \mathrm{P}$ $\left.<0,0001^{* * *}\right)$. Callinectes bocourti foi mais abundante em março e abril, sendo que as maiores capturas ocorreram nas estações da Lagoa Manguaba (Fig. 3). Para esta espécie, houve diferenças significativas tanto por mês (ANOVA: $\left.\mathrm{F}_{11,127}=2,61 ; \mathrm{P}<0,0049 * *\right)$, quanto por estação (ANOVA: $\mathrm{F}_{11,127}=3,14 ; \mathrm{P}<0,0008^{* *}$ ). Callinectes ornatus foi mais abundante em janeiro, março e abril, sendo mais comumente encontrada nas estações dos canais de ligação. Para C. ornatus, não houve diferenças significativas nas capturas por mês (ANOVA: $\mathrm{F}_{11.127}=1,51 ; \mathrm{P}>0,1353$ ), mas por estação sim (ANOVA: $\mathrm{F}_{11,127}=8,23 ; \mathrm{P}<$ $\left.0,0001^{* * *}\right)$.
A mesma análise da abundância numérica foi feita para as principais espécies de Palaemonidae (Fig. 4). Macrobrachium acanthurus foi mais abundante entre julho e outubro, especialmente nas estações com baixa salinidade, como a 1 e 9. Para M. acanthurus, houve diferenças significativas nas capturas por mês (ANOVA: $\mathrm{F}_{11,127}=2,84$; $\mathrm{P}<$ $0,0023^{* *}$ ) e por estação (ANOVA: $\mathrm{F}_{11,127}=4,28$; $\left.\mathrm{P}<0,0001^{* * *}\right)$. Palaemon pandaliformis foi mais abundante entre julho e novembro, sendo que mais de $80 \%$ dos exemplares foram capturados na estação 6 , mangue.

Os resultados da análise de variância para P. pandaliformis evidenciaram não haver diferenças significativas por mês (ANOVA: $\mathrm{F}_{11,127}=0,99$; $\mathrm{P}>0,4609)$, mas estas foram significativas por estação (ANOVA: $\mathrm{F}_{11,127}=2,33$; $\mathrm{P}<0,0122^{*}$ ). Macrobrachium olfersii foi mais abundante de julho a outubro, e ocorreu mais próxima das desembocaduras dos rios (Fig. 4). As diferenças nas capturas para $M$. olfersii não foram significativas por mês (ANOVA: $\mathrm{F}_{11,127}=1,17 ; \mathrm{P}>0,3145^{* *}$ ),
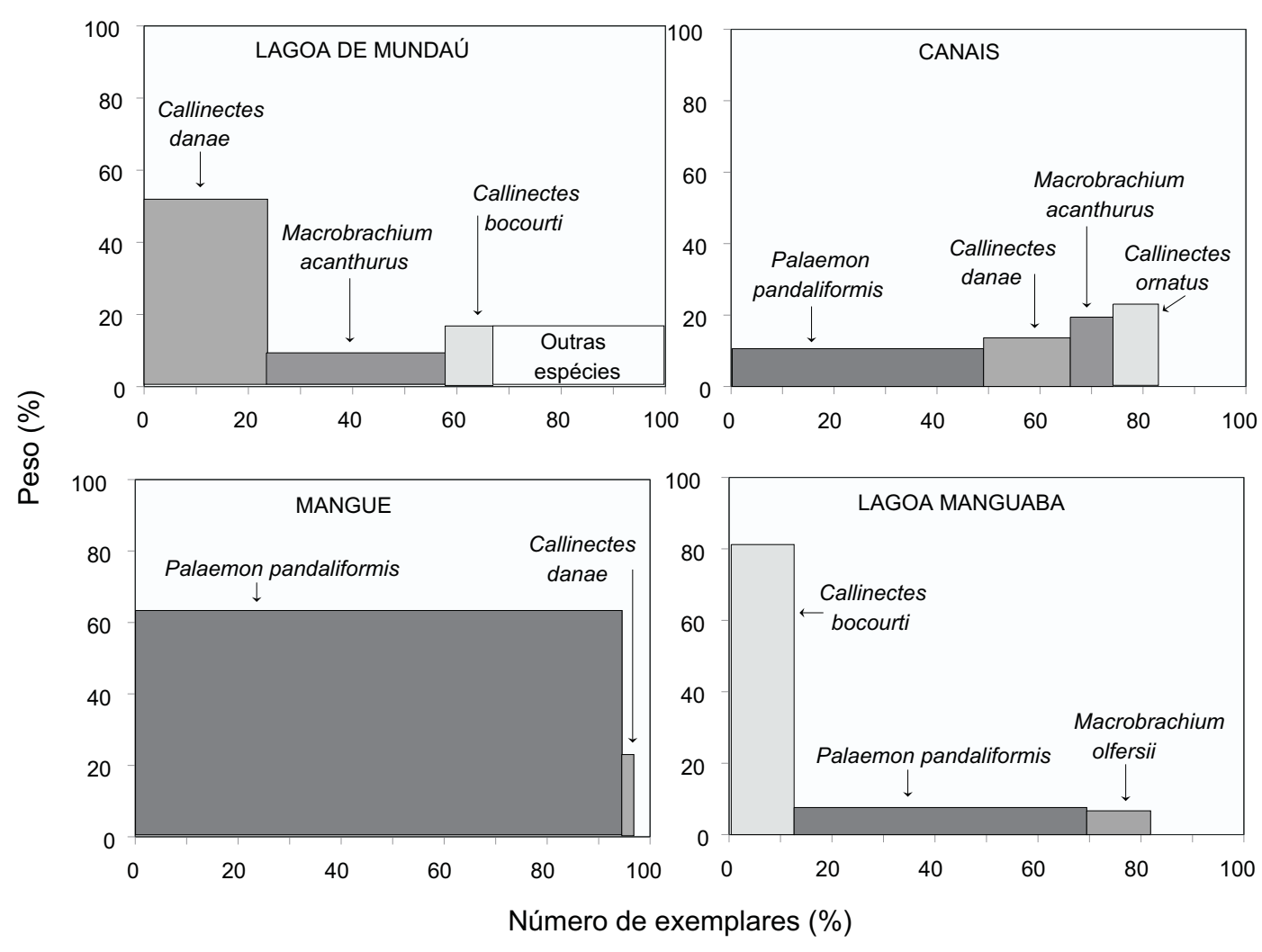

Fig. 2 - Abundância em número e em biomassa das espécies de macrocrustáceos predominantes nos subsistemas do complexo lagunar Mundaú/Manguaba. 
Callinectes danae
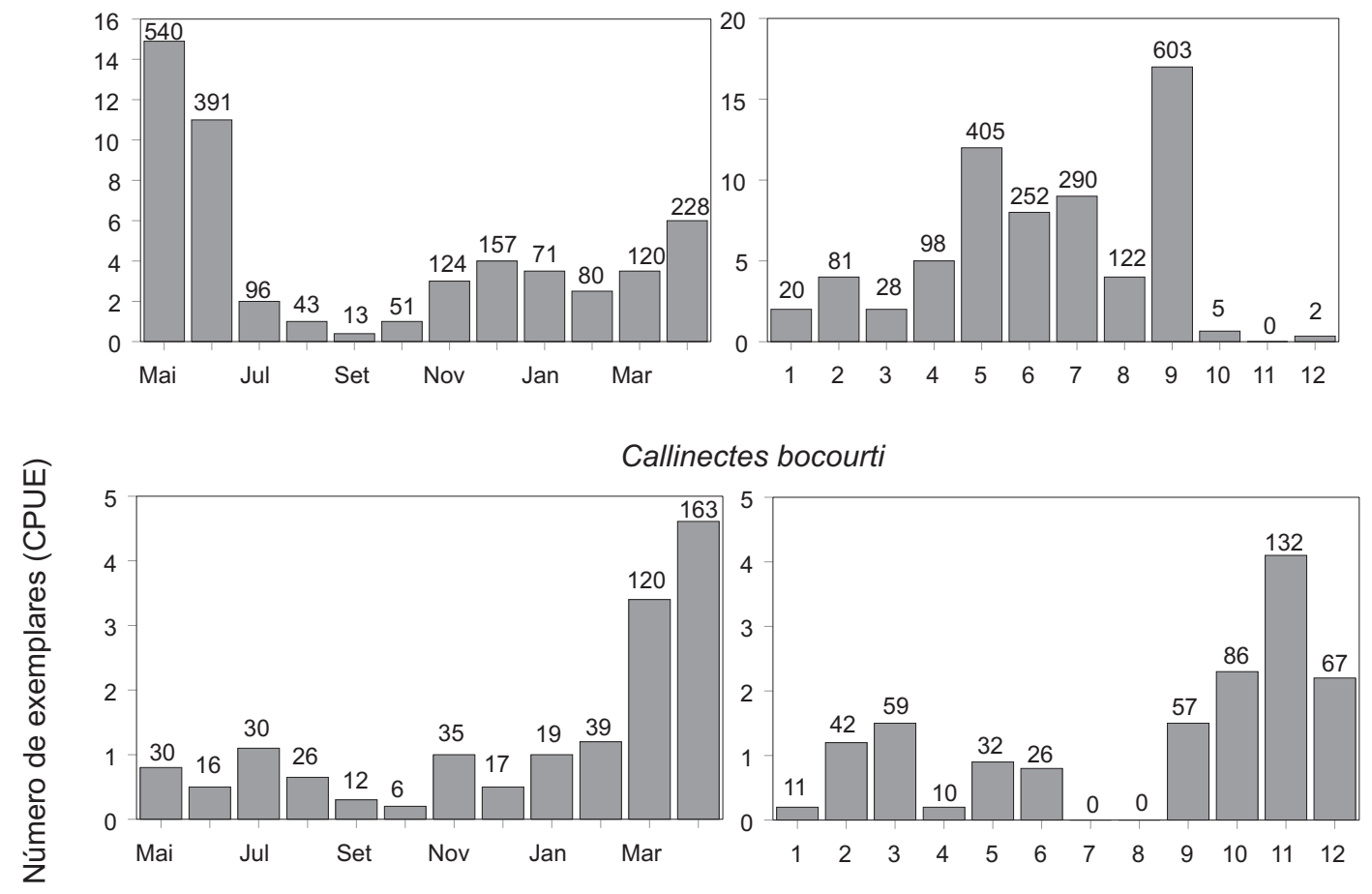

Callinectes ornatus
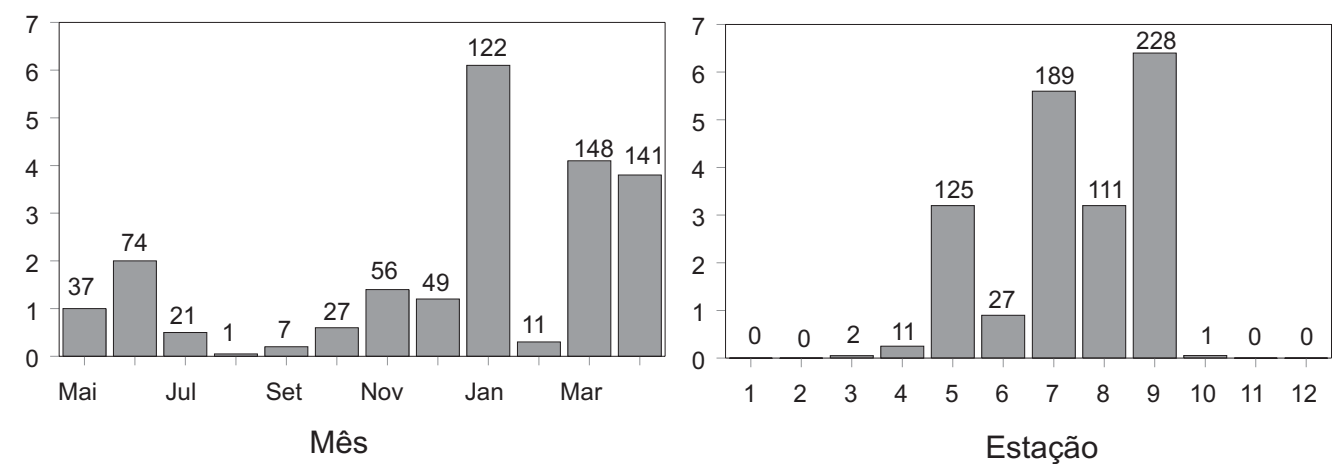

Fig. 3 - Abundância numérica por mês e estação de coleta das principais espécies de macrocrustáceos portunídeos do complexo lagunar Mundaú/Manguaba. O número de exemplares coletados encontram-se acima de cada barra.

mas por estação sim (ANOVA: $\mathrm{F}_{11,127}=4,99 ; \mathrm{P}<$ $0,0001 * * *)$.

Nas principais espécies de Portunidae, $C . d a-$ nae foi mais abundante em salinidade entre $5 \%$ e $9 \%$, C. bocourti, em salinidades menores de $14 \%$, enquanto $C$. ornatus, em salinidades superiores a 20\%o (Fig. 5). Nos Palaemonidae, M. acanthurus e $M$. olfersii foram mais abundantes em salinidades inferiores a 5\%o, enquanto P. pandaliformis, entre as salinidades de $15 \%$ a $19 \%$ (Fig. 5).
Foram feitas análises de agrupamentos para evidenciar a relação de abundância entre as dez espécies de macrocrustáceos mais importantes para o sistema lagunar Mundaú/Manguaba, baseadas por mês e estação de coleta (Fig. 6). Por mês de amostragem, ficou evidenciada a formação de dois grupos de espécies (Fig. 6A). O grupo I ficou caracterizado pelo predomínio de portunídeos, cujas abundâncias maiores ocorreram no período de estiagem, quando a salinidade no sis- 
Macrobrachium acanthurus
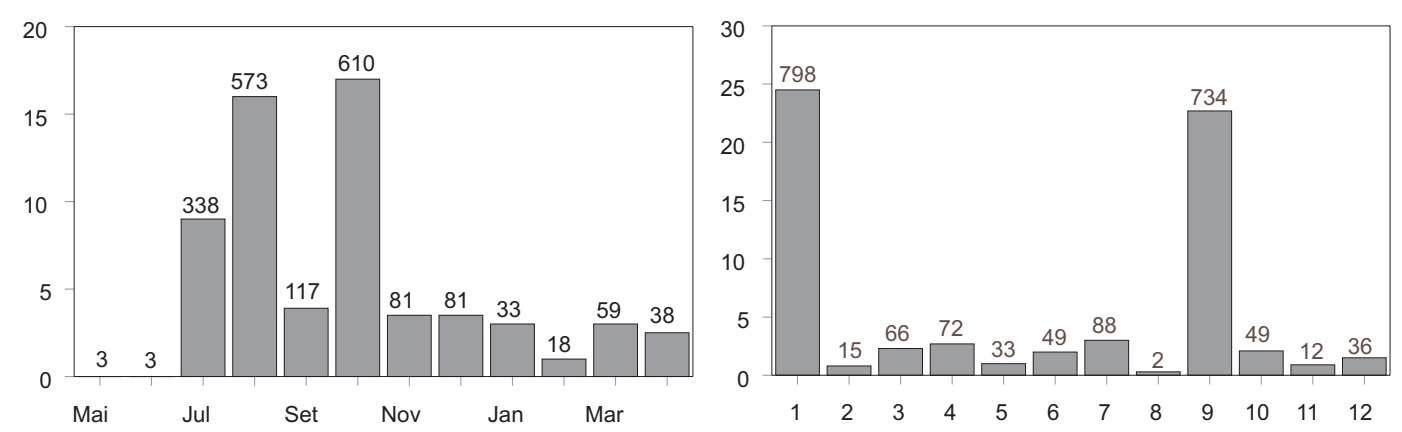

Palaemon pandaliformis
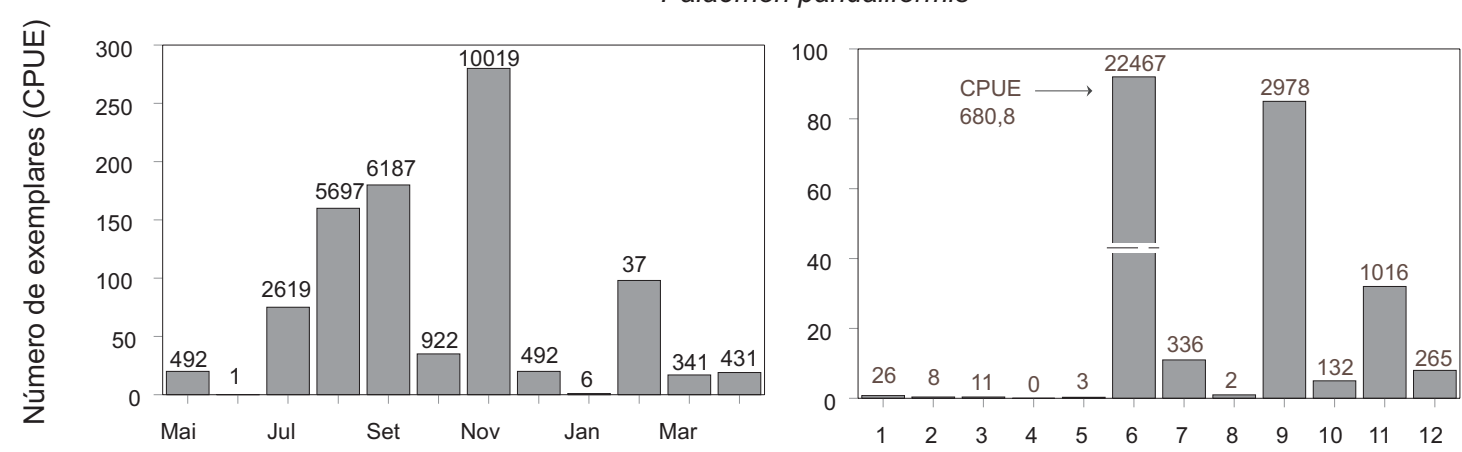

Macrobrachium olfersii
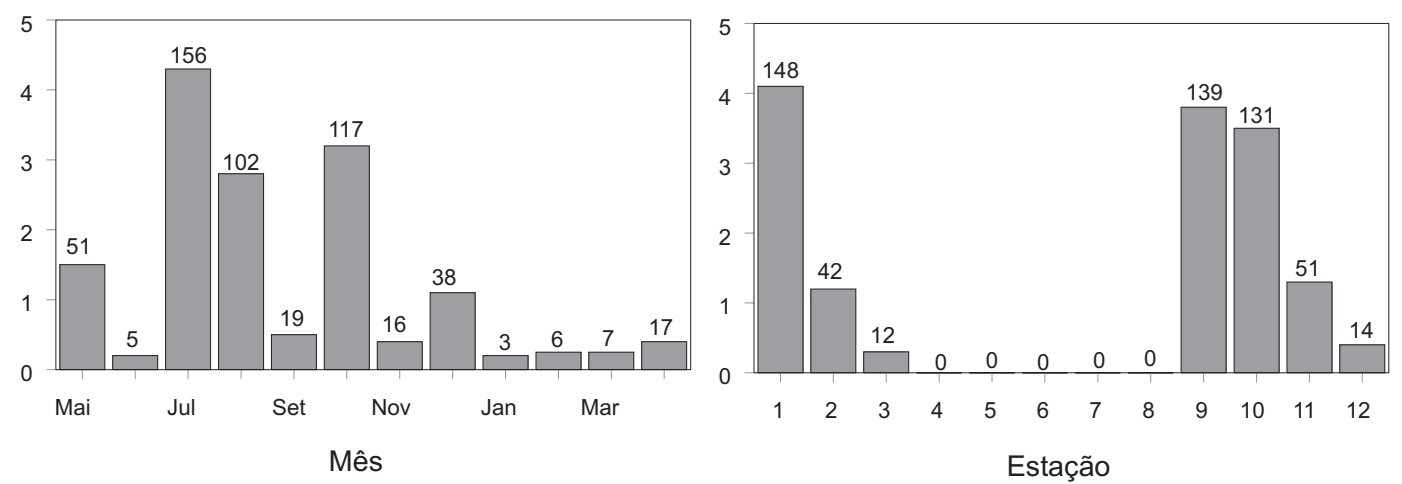

Fig. 4 - Abundância numérica por mês e estação de coleta das principais espécies de macrocrustáceos palaemonídeos do complexo lagunar Mundaú/Manguaba. O número de exemplares coletados encontra-se acima de cada barra.

tema atinge valores mais altos. O grupo II foi representado principalmente pelos palaemonídeos, cujas abundâncias foram maiores no período de chuvas, quando a salinidade em todo o sistema fica ao redor de $2 \%$.

A análise de agrupamento por estação de coleta também ressaltou a presença de dois grupos. O grupo I ficou restrito às espécies pertencentes aos portunídeos, as quais foram mais abundantes nas estações dentro e próximas aos canais de ligação entre as lagoas (Fig. 6B). O grupo II ficou caracterizado pela presença de palaemonídeos e peneídeos, os quais foram mais abundantes nas estações mais próximas às desembocaduras dos rios Mundaú e Paraíba do Meio. Palaemon pandaliformis ficou isolada, pois sua abundância 
TABELA 1

\begin{abstract}
Abundância numérica e em biomassa das espécies de macrocrustáceos capturadas no sistema lagunar Mundaú/ Manguaba de maio de 1988 a abril de 1989 baseado na captura por unidade de esforço (CPUE).
\end{abstract}

\begin{tabular}{|c|c|c|}
\hline Espécies & $\begin{array}{c}\text { CPUE } \\
\text { Número }\end{array}$ & $\begin{array}{c}\text { CPUE } \\
\text { Peso (g) }\end{array}$ \\
\hline \multicolumn{3}{|l|}{ PORTUNIDAE } \\
\hline $\begin{array}{l}\text { Callinectes bocourti } \\
\text { Callinectes danae } \\
\text { Callinectes exasperatus } \\
\text { Callinectes larvatus } \\
\text { Callinectes ornatus } \\
\text { Callinectes sapidus }\end{array}$ & $\begin{array}{l}1,25 \\
4,59 \\
0,27 \\
0,71 \\
1,66 \\
0,09\end{array}$ & $\begin{array}{c}20,56 \\
35,07 \\
2,34 \\
5,37 \\
5,85 \\
1,38\end{array}$ \\
\hline \multicolumn{3}{|l|}{ PENAEIDAE } \\
\hline $\begin{array}{l}\text { Penaeus schmitti } \\
\text { Penaeus subtilis }\end{array}$ & $\begin{array}{l}0,35 \\
1,98\end{array}$ & $\begin{array}{l}0,51 \\
1,87\end{array}$ \\
\hline \multicolumn{3}{|l|}{ PALAEMONIDAE } \\
\hline $\begin{array}{l}\text { Macrobrachium acanthurus } \\
\text { Macrobrachium jelskii } \\
\text { Macrobrachium olfersii } \\
\text { Palaemon northropi } \\
\text { Palaemon pandaliformis }\end{array}$ & $\begin{array}{c}4,69 \\
0,03 \\
1,29 \\
0,66 \\
65,33\end{array}$ & $\begin{array}{c}6,67 \\
0,02 \\
1,49 \\
0,18 \\
10,77\end{array}$ \\
\hline \multicolumn{3}{|l|}{ ATYIDAE } \\
\hline $\begin{array}{l}\text { Atya scabra } \\
\text { Potimirim potimirim }\end{array}$ & $\begin{array}{c}<0,01 \\
0,20\end{array}$ & $\begin{array}{l}0,06 \\
0,03\end{array}$ \\
\hline $\begin{array}{l}\text { Número Total } \\
\text { Peso Total } \\
\text { Número de Lances }\end{array}$ & $\begin{array}{c}34656 \\
- \\
417\end{array}$ & $\begin{array}{c}- \\
38430,7 \\
417\end{array}$ \\
\hline
\end{tabular}

numérica total ficou praticamente relacionada à estação localizada no mangue.

$\mathrm{Na}$ análise de componentes principais, os autovalores dos três primeiros fatores explicaram $77,6 \%$ das variâncias de sete variáveis (Tabela 2). No primeiro fator, distância do mar teve um peso forte e negativo, enquanto substrato, salinidade e transparência tiveram valores altos e positivos acima de 0,70 . No segundo fator, vazão e temperatura tiveram valores altos, enquanto no terceiro apenas profundidade apresentou valor alto.

A análise de componentes principais evidenciou a formação de dois grupos de espécies relacionadas com as variáveis ambientais (Fig. 7). Um grupo relacionou as espécies marinhas que utilizam o estuário como área de criação, e as principais variáveis que apresentaram os maiores pesos foram salinidade, transparência e tipo de substrato. Deste grupo fazem parte as seguintes espécies: $C$. danae, $C$. ornatus, $C$. larvatus, $P$. northropi e $P$. subtilis. O segundo grupo ficou representado pelas espécies que preferem águas mais doces, como: $M$. acanthurus, $M$. olfersii, $P$. pandaliformis e $C$. bocourti. As variáveis que mais se relacionaram com este grupo de espécies foram distância do mar e vazão. Penaeus scmitti apresentou-se isolada, pois esta espécie ocorreu com pouca abundância ao longo do ano, sendo que as variáveis analisadas não tiveram boa correlação com esta espécie dentro do estuário.

\section{DISCUSSÃO}

O sistema lagunar Mundaú/Manguaba, além de se caracterizar pela diversidade de habitats, os quais podem ser agrupados em quatro subsistemas, também se caracteriza pela diversidade de espécies de peixes (Teixeira \& Falcão, 1992), assim como pela diversidade de macrocrustáceos (Pereira-Barros, 1981; Silva, 1992). O principal recurso pesqueiro da região é o sururu (Mytella falcata) (Pereira-Barros \& 
Pereira-Barros, 1987), cujos bancos que se formam principalmente na Lagoa de Mundaú, certamente, criam microhabitats à parte, cuja complexidade deve contribuir com a distribuição e a abundância de vários organismos.

Para o Estado de Alagoas, foram mencionadas preliminarmente cerca de 204 espécies de crustáceos decápodas (Coelho et al., 1990). Este resultado confirma a importância do grupo, principalmente se levarmos em consideração a pequena extensão do litoral de Alagoas quando comparado a outros estados brasileiros.
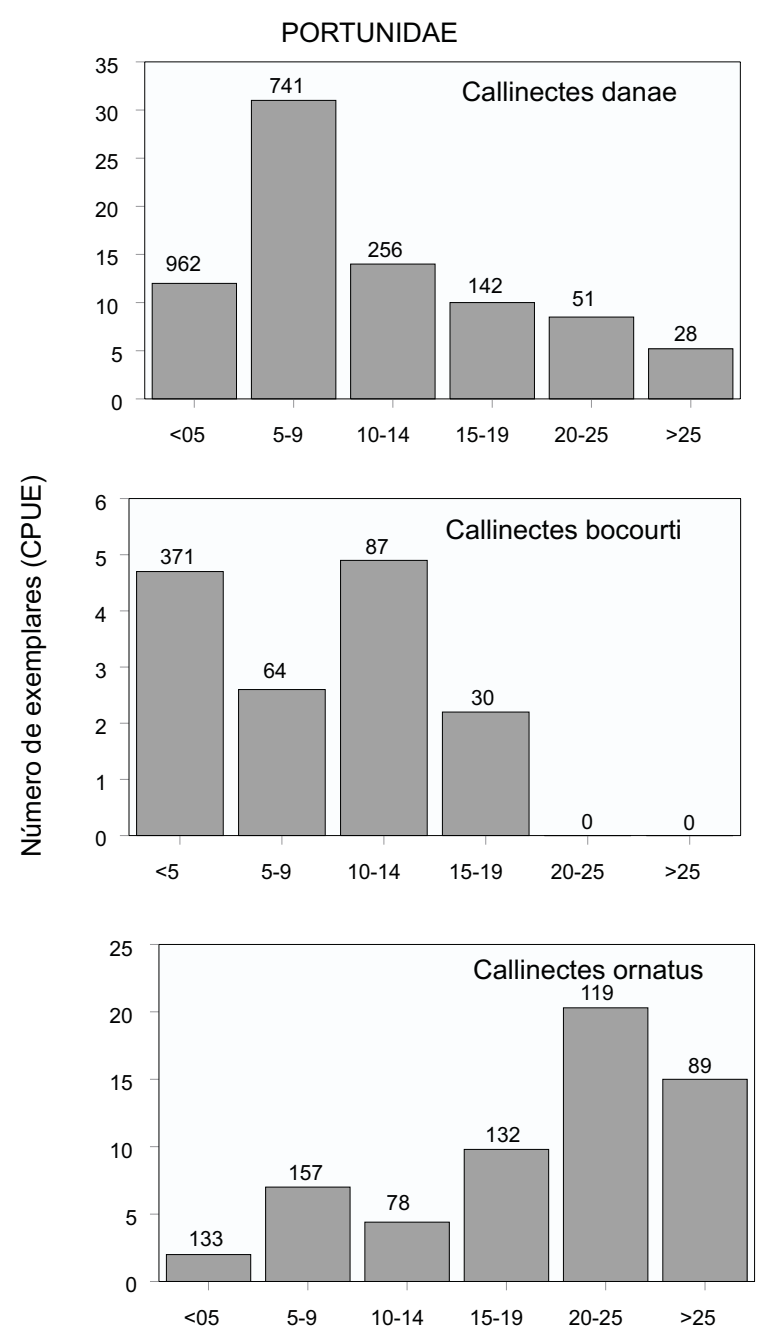

Os macrocrustáceos apresentam um papel relevante no que se refere às pescarias dentro do sistema lagunar. No entanto, o real valor das espécies parece ter sido negligenciado, uma vez que não é feita uma avaliação metódica da quantidade de crustáceos desembarcados nas várias colônias de pesca localizadas ao redor do sistema lagunar. Além das dificuldades de se amostrar nestas colônias, seria impossível obter dados das pescarias isoladas que são realizadas pela maioria das famílias que habitam nas proximidades do sistema lagunar.
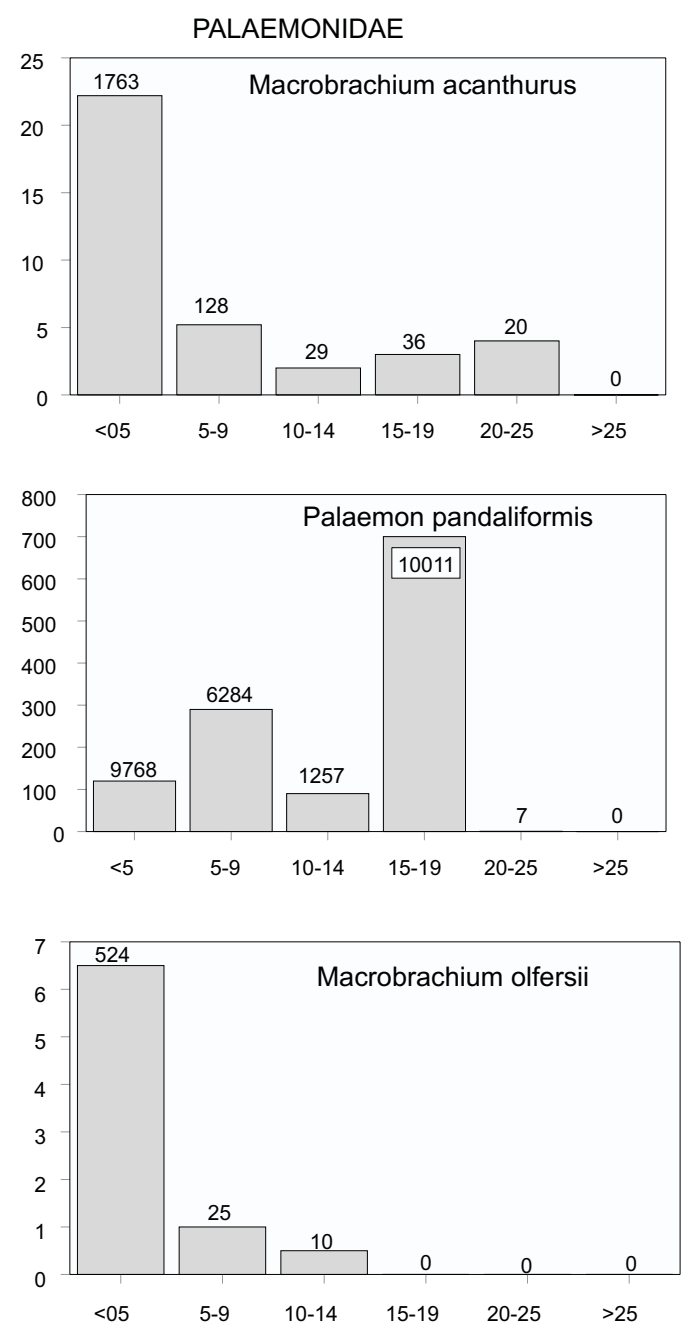

Salinidade (\%o)

Fig. 5 - Abundância numérica das principais espécies de macrocrustáceos portunídeos e palaemonídeos do complexo lagunar Mundaú/Manguaba de acordo com as classes de salinidade. O número de exemplares coletados encontra-se acima de cada barra. 
TABELA 2

Peso das variáveis ambientais da análise de componentes principais do complexo lagunar Mundaú/Manguaba.

\begin{tabular}{lccc}
\hline Variável & Fator $\mathbf{1}$ & Fator 2 & Fator 3 \\
\hline Distância do mar & $-0,87$ & $-0,04$ & 0,12 \\
Profundidade & 0,03 & 0,10 & 0,96 \\
Vazão & $-0,05$ & 0,85 & $-0,06$ \\
Substrato & 0,75 & 0,16 & 0,01 \\
Temperatura & 0,04 & $-0,87$ & $-0,17$ \\
Salinidade & 0,74 & $-0,38$ & 0,26 \\
Transparência & 0,70 & $-0,27$ & 0,50 \\
\hline Variância explicada & 2,39 & 1,75 & 1,28 \\
Variância cumulativa $(\%)$ & 34,2 & 59,3 & 77,6 \\
\hline
\end{tabular}

A

Distância Euclidiana

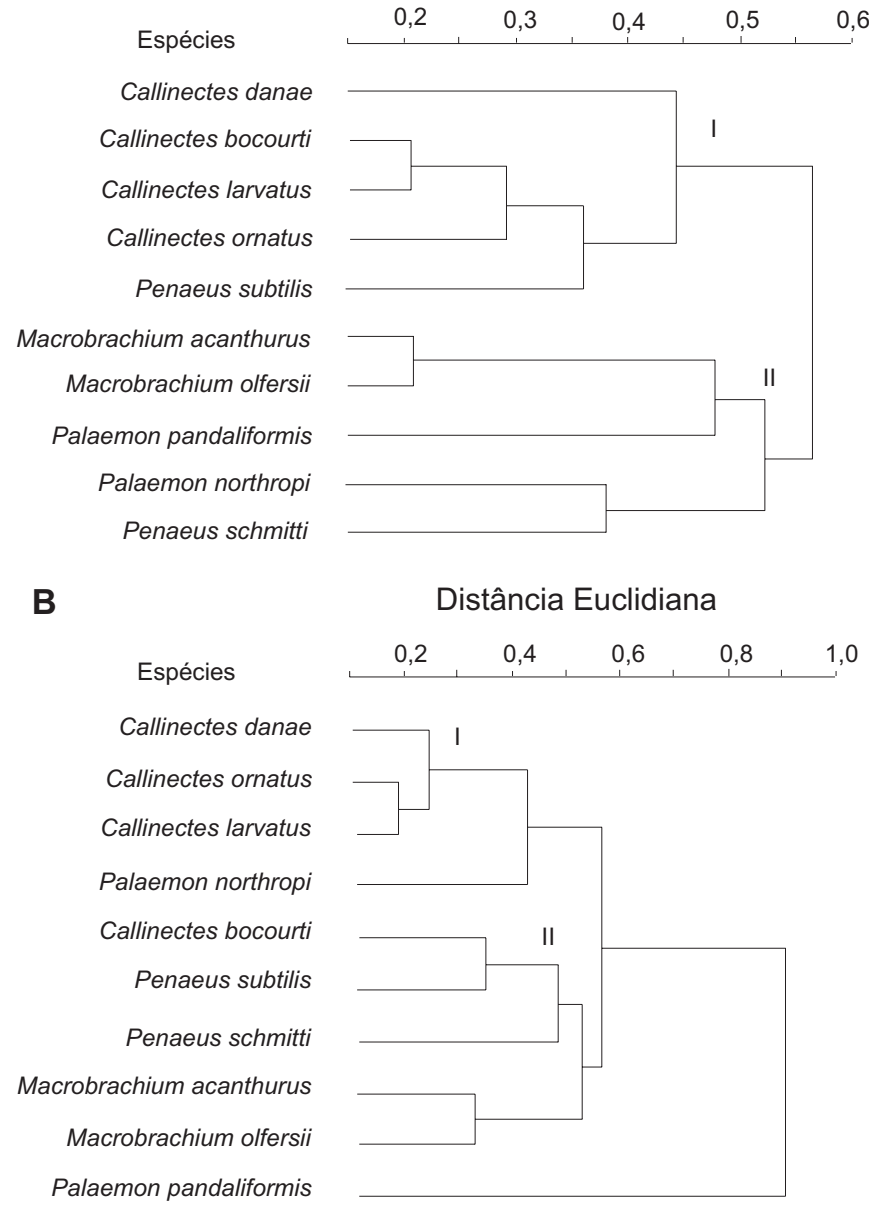

Fig. 6 - Análises de agrupamentos relacionando a abundância numérica das 10 espécies mais comuns de macrocrustáceos do complexo lagunar Mundaú/Manguaba. A) relacionamento entre abundância e mês de amostragem; B) relacionamento entre abundância e estação de amostragem. 


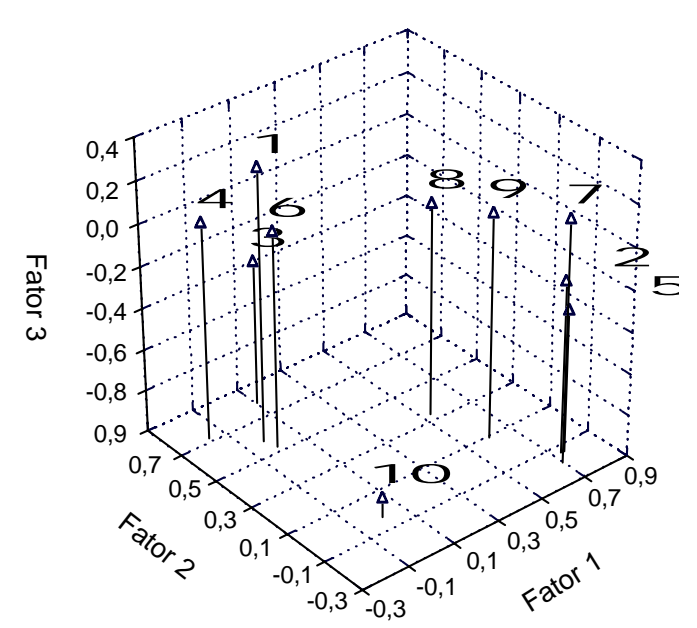

Fig. 7 - Análise de componentes principais dos crustáceos decápodas mais relevantes do complexo lagunar Mundaú/ Manguaba. 1 - Callinectes bocourti, 2 - C. danae, 3 Macrobrachium acanthurus, $4-M$. olfersii, $5-C$. ornatus, 6 - Palaemon pandaliformis, 7 - C. larvatus, 8 - Penaeus subtilis, 9 - Palaemon northropi, 10 - Penaeus schmitti.

Dentre as 15 espécies capturadas neste estudo, praticamente quase todas são usadas para consumo humano. São exceção a esta observação as espécies $P$. potimirim e A. scabra. A primeira por ser muito pequena e pouco abundante, a segunda provavelmente devido à baixa abundância. Palaemon pandaliformis, apesar do pequeno tamanho, é capturada com redes de arrasto e outras redes manuais. A seguir, esta espécie é seca ao sol, para posteriormente ser transformada em farinha. As espécies pertencentes ao gênero Callinectes são as mais procuradas para consumo, especialmente quando se encontram em ecdise.

Os aspectos relacionados à importância dos siris do gênero Callinectes no estuário de Mundaú/Manguaba foram evidenciados amplamente em vários estudos (por exemplo, Pereira-Barros, 1969, 1981; Pereira-Barros \& Travassos, 1975; entre outros).

Silva (1992) comparou a abundância da fauna macrobentônica do complexo Mundaú/Manguaba utilizando dragagens em gradientes batimétricos. O autor observou a presença de 6 espécies de crustáceos decápodas, sendo 4 espécies pertencentes ao gênero Callinectes, mais Palaemon pandaliformis e Macrobrachium acanthurus. Esses resultados, quando comparados aos obtidos neste estudo, evidenciam as espécies de macrocrustáceos mais comuns dentro do estuário de Mundaú/Manguaba, tanto nas áreas rasas quanto nas mais profundas. Já na parte externa da boca da barra nova do sistema Mundaú/Manguaba, capturas com rede de arrasto evidenciaram o predomínio na abundância numérica de camarões, como Xiphopenaeus kroyeri, Palaemon schmitti e Penaeus schmitti (Teixeira \& Falcão, 1992).

Dentre os fatores abióticos analisados no presente estudo, a salinidade parece ser o mais importante como regulador da distribuição e abundância dos macrocrustáceos no complexo estuarino Mundaú/Manguaba. Efeitos da salinidade influenciando o desaparecimento do sururu dentro do complexo estuarino Mundaú/Manguaba foram amplamente discutidos por Asbury (1979). A salinidade também é um fator importante que controla a distribuição de muitas espécies de peixes dentro do complexo estuarino, como por exemplo os bagres (Melo \& Teixeira, 1992), os eleotridídeos (Teixeira, 1994), os gerreídeos (Teixeira \& Helmer, 1997) e o camurim Centropomus undecimalis (Teixeira, 1997), entre outros, os quais apresentaram altas proporções de crustáceos em seus conteúdos estomacais. A temperatura pouco flutua ao longo do ano. O período de chuvas, no inverno, transforma o sistema em um grande manancial de água doce. Apesar disso, o efeito direto é sobre a salinidade, sendo que os limites da região estuarina são empurrados para fora da boca da estreita barra que liga o sistema lagunar ao oceano (Fig. 1).

Concomitantemente, os valores de transparência diminuem durante o período de chuvas devido à grande quantidade de sedimentos trazidos pelos rios. Os "blooms" de algas que ocorrem principalmente durante a primavera contribuem para a depleção nas taxas de saturação do oxigênio dissolvido em determinadas áreas das lagoas, ocasionando a morte principalmente de peixes com baixa capacidade de natação (Teixeira \& Falcão, 1992). Os crustáceos, aparentemente, são mais resistentes às depleções nas taxas de oxigênio dissolvido.

Os vários subsistemas do complexo estuarino Mundaú/Manguaba são dominados por diferentes espécies. De uma maneira geral, as espécies de pequeno porte, como os palaemonídeos, dominam em número de organismos, mas as de maior porte, como os portunídeos, dominam em 
biomassa. A exceção a esse padrão foi observada na estação localizada no mangue, onde $P$. pandaliformis dominou tanto em número quanto em biomassa.

A ocupação do ambiente estuarino pelos macrocrustáceos parece estar relacionada a diferentes movimentos para dentro do sistema. A maioria dos portunídeos e os peneídeos move-se do oceano para dentro do sistema estuarino, enquanto os palaemonídeos se movem a partir do aporte de água doce que margeia a lagoa. As espécies que ocupam a Lagoa de Mundaú estão mais sujeitas a trocas bruscas dos fatores abióticos, especialmente no que se refere à salinidade, enquanto as espécies que ocupam a Lagoa Manguaba encontram um ambiente mais estável. Devido ao sistema de canais, a água do oceano não consegue atingir a Lagoa Manguaba em uma maior proporção. De qualquer maneira, o sistema lagunar está sujeito a flutuações nos fatores abióticos mesmo durante um ciclo de maré. Por exemplo, o período de chuvas e o conseqüente aporte de água doce podem variar de ano para ano, sendo que são esperadas variações mensais e por estação na abundância das espécies mais frequientes, como as mostradas nas Figuras 3 e 4.

A análise da similaridade na abundância das 10 espécies predominantes mostrou um caráter importante no padrão de distribuição. As espécies pertencentes à família Portunidae (particularmente o gênero Callinectes) formaram um dos grupos fortes, enquanto o outro grupo ficou mais relacionado aos representantes da família Palaemonidae.

O agrupamento de espécies mais similares morfologicamente evidencia padrões semelhantes no que se refere aos movimentos para dentro do sistema estuarino. No entanto, as espécies dominantes apresentaram também uma certa divisão espaço-temporal, assim como preferências por diferentes teores de salinidade (Figuras 3, 4 e 5). Este resultado também foi corroborado pela análise de componentes principais, a qual também segregou os grupos de espécies, como aquelas mais relacionadas à ocupação de ambientes mais próximos à água doce, assim como outro grupo composto por espécies estuarinas dependentes, em apenas uma fase do ciclo de vida.

O presente estudo avaliou alguns aspectos da importância dos macrocrustáceos nas partes rasas dentro do complexo estuarino Mundaú/Manguaba. Apesar do sistema ser dominado pelas áreas rasas, a abundância desses organismos nas partes mais profundas deveria ser analisada em estudos posteriores. Aspectos da biologia, como reprodução e alimentação, também deveriam ser avaliados no futuro.

A reprodução evidenciaria os aspectos biológicos que contribuem para a dominância de determinadas espécies e conseqüente recrutamento para dentro do sistema, enquanto a alimentação poderia evidenciar aspectos relacionados à divisão de recursos alimentares para as mesmas.

Entretanto, para garantir a renovação dos estoques de macrocrustáceos decápodas dentro do sistema estuarino, é necessário o desenvolvimento de melhores planos de administração dos estoques pesqueiros.

Agradecimentos - Este estudo foi financiado pela Comissão Interministerial para os Recursos do Mar (CIRM) e CNPq (RLT, Processo №. 302657/87-8). Gostaríamos de agradecer ao auxílio de Gérson A. Silva nas coletas e a Jorge Pablo Castello pelo apoio prestado durante os trabalhos de campo.

\section{REFERÊNCIAS BIBLIOGRÁFICAS}

ASBURY, C. E., 1979, Salinity of Mundaú lagoon, Brazil, 1972-1978, in relation to disappearance of sururu, My4tella falcata. B. Núcl. Est-s Ci-s Mar, 1: 17-26.

COELHO, P. A. \& RAMOS, M. A., 1972, A constituição e a distribuição da fauna de decápodos do litoral leste da América do Sul entre as latitudes de $5^{\circ} \mathrm{N}$ e $39^{\circ} \mathrm{S}$. Trab. Oceanogr. Univ. Fed. Pe., Recife, 13: 133-236.

COELHO, P. A. \& LACERDA, P. R., 1990, Levantamento preliminar dos braquiuros (Crustacea: Decapoda) dos arrecifes da praia de Piedade, Jaboatão, PE. An. Soc. Nordest. Zool., 3: 35-42.

COELHO, P. A. \& REGIS, R. A., 1990, Litoral do Pará e Maranhão: Crustacea Isopoda. An. Soc. Nordest. Zool., 3: 9-19.

COELHO, P. A., RAMOS-PORTO, M \& MELO, G. A. S., 1990, Crustáceos decápodas do Estado de Alagoas. An. Soc. Nordest. Zool., 3: 21-34.

MELO, S. C. \& TEIXEIRA, R. L., 1992, Distribuição, reprodução e alimentação de Cathorops spixii e Arius rugispinis (Pisces, Ariidae) do complexo Mundaú/Manguaba, Maceió, AL. Rev. Brasil. Biol., 52(1): 169-180.

MULAIK, S. A., 1972, The Foundations of Factor Analysis. McGraw-Hill Co., New York.

PEREIRA-BARROS, A. T. L. \& PEREIRA-BARROS, J. B., 1987, Importância sócio-econômica do sururu (Mytella falcata - Mollusca, Mytilidae) para a população da cidade de Coqueiro Seco. Bol. Estud. Ciênc. Mar, 6: 49-64.

PEREIRA-BARROS, J. B., 1969, Informes sobre a pesca na Lagoa Mundaú, Alagoas (peixe, camarão e siri). Sér. Est. Pesca, Recife, SUDENE, 9(2): 45-60. 
PEREIRA-BARROS, J. B. \& TRAVASSOS, I. B., 1975, Informes sobre a pesca e biologia do siri tinga (Callinectes danae) e gurjaú (Callinectes bocourti) na lagoa Mundaú, Maceió, Alagoas. Sér. Est. Pesca, Recife, SUDENE, 2: 5-13.

PEREIRA-BARROS, J. B., 1981, Sobre a ocorrência de siris do gênero Callinectes em Alagoas. Bol. Estud. Ciênc. Mar, 5: 14-17.

RAMOS, M. \& COELHO, P. A., 1990, Sinopse dos crustáceos decápodos brasileiros. An. Soc. Nordest. Zool., 3: 93-111.

SEDBERRY, G. R. \& CARTER, J., 1993, The fish community of a shallow tropical lagoon in Belize, Central America. Estuaries, 16(2): 198-215.

SILVA, C. S., 1992, Distribuição e abundância da fauna macrobentônica do complexo estuarino Mundaú/ Manguaba (Alagoas, Brasil). Bol. Estud. Ciênc. Mar, 6: 45-64.

SOKAL, R. R. \& ROHLF, F. J., 1981, Biometry. W.H. Freeman and Co., San Francisco.
TEIXEIRA, R. L. \& FALCÃO, G. A. F., 1992, Composição da fauna nectônica do complexo lagunar Mundaú/Manguaba, Maceió, AL. Atlântica, Rio Grande, 4: 43-58.

TEIXEIRA, R. L. \& FALCÃO, G. A. F., 1992, Nota sobre os peixes e macrocrustáceos que ocorrem próximo à desembocadura do complexo lagunar Mundaú/Manguaba (Alagoas, Brasil). Bol. Estud. Ciênc. Mar, 8: 5-12.

TEIXEIRA, R. L., 1994, Abundance, reproductive period, and feeding habits of eleotridid fishes in estuarine habitats of north-east Brazil. Jour. Fish Biol., 45: 749-761.

TEIXEIRA, R. L., 1997, Distribution and feeding habits of the young common snook, Centropomus undecimalis (Pisces, Centropomidae), in the shallow waters of a tropical Brazilian estuary. Bol. Mus. Biol. Mello Leitão (N. Sér.) 6: 35-46.

TEIXEIRA, R. L. \& HELMER, J. L., 1997, Ecology of young mojarras (Pisces, Gerreidae) occupying the shallow waters of a tropical estuary. Rev. Brasil. Biol., 57(4): 637-646. 